This item was submitted to Loughborough's Research Repository by the author.

Items in Figshare are protected by copyright, with all rights reserved, unless otherwise indicated.

\title{
A decision model for a strategic closed-loop supply chain to reclaim End-of- Life Vehicles
}

PLEASE CITE THE PUBLISHED VERSION

https://doi.org/10.1016/j.ijpe.2017.10.005

PUBLISHER

(C) Elsevier

VERSION

AM (Accepted Manuscript)

\section{PUBLISHER STATEMENT}

This work is made available according to the conditions of the Creative Commons Attribution-NonCommercialNoDerivatives 4.0 International (CC BY-NC-ND 4.0) licence. Full details of this licence are available at: https://creativecommons.org/licenses/by-nc-nd/4.0/

\section{LICENCE}

CC BY-NC-ND 4.0

\section{REPOSITORY RECORD}

Shankar, Ravi, Shisam Bhattacharyya, and Alok K. Choudhary. 2019. "A Decision Model for a Strategic Closed-loop Supply Chain to Reclaim End-of-life Vehicles”. figshare. https://hdl.handle.net/2134/27947. 


\title{
A Decision Model for a Strategic Closed-loop Supply Chain to Reclaim End-of-Life Vehicles
}

\begin{abstract}
$\underline{\text { Abstract }}$
Closed-loop supply chain strategies for End-of-Life (EOL) product and its logistics operations have received greater attention in the last few years. These strategies include warranty-based acquisition, quantity-based acquisition, quality-based acquisition, centrally coordinated logistics operations and third party logistics operations. This research connects two aspects of an automobile's closed-loop supply chain strategy. The first aspects is the optimal transportation planning for raw material parts, newly manufactured and end of life product in a closed-loop supply chain keeping the demand, collection rate and capacity of associated facilities in the network as functional parameters. A mixed integer mathematical model is formulated for the closed-loop supply chain network with a multi-echelon inventory, multi-period planning and multi-product scenario all used to compute the maximum contribution margin generated through different strategies. The second aspect pertains to using the output of this model for handling the sequential form of cooperative game. The proposed two-phase decision model analyzes the 'realization times' and 'delivery limits' of different products as an indicator of swapping different strategies. Three instances have been analyzed to understand and validate the applicability of the model. In these scenarios, sensitivity analysis has been performed and managerial insights are presented which provide flexibility in decision making.
\end{abstract}

Keywords: closed-loop supply chain; mixed integer programming; sequential game; strategy; optimization 


\section{Introduction}

An automobile supply chain is a network of ancillary suppliers, an assembly plant, stores and logistics channels. The management thereof helps to procure raw materials, convert them to finished products, and then distribute final products in an efficient way to customers (Özceylan et al. 2012; Pishvaee et al. 2011). This situation is revisited to include reverse flows, which would reduce pressure on natural resources and limit environmental problems. The uninterrupted availability of raw materials is a key requisite to profit generation in the long run. Therefore, we find a growing interest in the recovery of raw materials from the used products, collected from customers, rather than the conventional metal extraction processes (Lee et al. 2009). Subsequently, overall lifecycle management of products and other logistics solutions related to supply chain are integrated comprehensively (Yang et al. 2009). The strategic closed-loop supply chain framework is one of the most prudent approaches towards sustainability and offers opportunities for long term business survival. The strategic closed-loop supply chains (CLSCs) consist of two stages: forward logistics and reverse logistics. For forward logistics, next to ancillary suppliers and assembly plants, deliveries are made to the dealers to satisfy their customers' demands (Schultmann et al. 2005). For the reverse logistics, the used products come back from customers to dealers, and are worked on at collection centers, End-ofLife Vehicle (ELV) dismantlers, central service centers and trash yards to segregate materials to be either dismantled, refurbished or dumped (Wang and Hsu 2010, Paksoy et al. 2011). CLSC activities include acquisition, selection, disassembly, cannibalization and mechanical processing to improve utilization of resources, green image branding, competence development for enterprises, achieving service level, and thus supporting the contribution margin or overall profit (Lebreton 2007 and Demirel et al. 2008). There are 3200 ERMs operating in the city of New Delhi and overall 100,000 families are expected to be dependents. The disassembly units are situated both in the outskirts as well as in densely populated areas. For ERMs, environmental policies of the concerned authorities are informal in nature, leading to heavy environmental pollution. In this work, a strategic closed-loop supply chain network model is presented, which uses a mixed integer profit maximization model to optimize a supply chain network. The forward supply chain network includes raw material suppliers, plants, retailers, and customers, while the reverse supply chain network consists of dealers, collection centers, ELV dismantlers, central servicing centers, ancillary suppliers and assembly plants. A combined forward and reverse logistics model has been developed for a single planning horizon with four periods, where each period is of one-month duration, and the entire network is 
spread across a single time zone. For the purpose of analysis, we presume that different parts have almost the same assembly rates. Raw materials and parts are classified in terms of their property and cost, respectively. However, raw materials and parts required for products are similar in nature. After the collection of ELVs from the customers, the end products or used parts are kept at the dealer's premise as dealers are located near to their customers. According to the demand for non-recycled used products and recycled products, and these are sent to assembly plants via collection centers, ELV dismantlers and central service center to disassemble and refurbish the end of life product. The leftovers are then transferred to the trash yard to remove the raw materials needed by ancillary suppliers. The extracted material is reused in the next period. Therefore, assembly plants produce re-manufactured automobiles, which are aligned and supported by ancillary suppliers and central service centers. In the proposed model, we had developed a two - phase mixed integer linear programming model, which maximizes contribution margin or profit. This is simulated under different sets of strategies. Strategies are based on incentives and contracts and these are widely used in automobile refurbishment (Lebreton 2007; Schultmann et al. 2005). Transportation cost, procurement cost, processing cost, and the fixed cost are involved in opening or closing of potential facilities of the CLSC network like ancillary suppliers, assembly plants and dealers. Here, we considered two decision makers of the same firm (OEM) who are trying to impose two different sets of strategies. A co-operative game is played to compute the best possible combination of strategies, which can yield maximum profit. Hence, the simultaneous equation of game theory with perfect information under a mixed strategy is used to find the equilibrium or saddle point. From a pay-off matrix, probabilities are calculated through a sequential equation for each player and their different sets of strategies. In this model, the decision makers are advised to use these probabilities as optimal realization times (RLTs) and delivery limits for each strategy. According to the realization time each decision makers can schedule the strategies across the entire planning horizon of four months. Such scheduling and swapping of strategies would lead to overall profit maximization. The decision makers support the OEM in production planning of all categories of product to obtain maximum profit throughout the planning horizon (all four periods) by swapping or interchanging alternative strategies after certain delivery limits and / or after certain time intervals (RLTs). The research context here is the Indian automotive sector. India has achieved extraordinary growth in the last decade after the economic liberalization measures undertaken in 1991. The automotive mission plan 2006-2016 released by the 'Ministry of Heavy Industries and Public Enterprise' declared the following mission: “To emerge as the destination of choice in the world for design and manufacture of automobiles and auto-components with output 
reaching a level of US\$ 145 billion accounting for more than $10 \%$ of the GDP and providing additional employment to 25 million people by 2016". Apart from profit, OEMs are motivated by take - back laws imposed by the regulatory authority (Malhotra, 2011). On the basis of the proposal, the Society of Indian Automotive Manufacturers (SIAM) created a recycling task force. In Northern India, it was found that ELV reprocessing is mostly organized by an informal unregulated sector, otherwise known as external remanufacturers (ERMs) (Chaturvedi et al 2012). Then, our analysis examines the effects of parameters such as demand, capacities and collection rates of, optimal shipments and total profit. The paper is further organized as follows. Section 2 presents a brief survey of existing literature in this area. In Section 3, the proposed two - phase mixed integer programming model is presented with sequential linear equation for the pay-off matrix. Results of computational experiments using sample instances are given in Section 4, and the conclusions and scope for future studies are presented in Section 5.

\section{Literature review}

In spite of a considerable amount of research already having been carried out on supply chain network design, problems related to logistic routing and scheduling, fleet size optimization, warehouse load balancing, etc. have created sufficient awareness of the importance of incorporating reverse and CLSC activities. The literature on the strategic CLSC network design problem and its variants are quite rich, and the reader is referred to the books of Flapper et al. (2005), Lebreton (2007), and Ferguson and Souza (2010), the book review by McGovern (2009), and the comprehensive survey by Srivastava (2007). Akcal et al. (2009) provide a wide coverage of state of the art models and solution algorithms. Although there have been many studies on reverse logistics, there is still a gap that needs to be filled when it comes to modelling for the strategies of the CLSC. This work provides several pointers to the relevant literature. A CLSC model for remanufacturing has been studied by Ravi et al. (2013), Jayaraman et al. (1999) and Özceylan et al. (2012) in which decisions relevant to shipment and remanufacturing of a set of products, as well as establishment of facilities to store the remanufactured products, are taken into consideration. The model is in the form of a binary integer programming formulation that minimizes a total cost function involving the opening of any facility, shipment, remanufacture, and inventory. A reverse logistics network design problem is analysed for the impact of product return flows on logistics networks by Fleischmann et al. (2001). Krikke et al. (2003) presented a quantitative model to support decision-making concerning both the design structure of a product and its logistic 
network. Environmental impacts are also calculated by linear energy and waste functions. Economic costs are modelled as linear functions of volumes with a fixed set-up component for all CLSC facilities. Guide et al. (2003) took a contingency approach in running CLSCs with end of life product recovery. Paksoy et al. (2011) proposed a mixed integer programming model to optimise a CLSC problem, which captured the trade-offs between various costs, including those of excretions. Pishvaee et al. (2011) proposed a robust optimization model to address the intrinsic uncertainty of input data in a CLSC network problem.

Jayaraman (2006) took an analytical approach towards production planning and material handling for CLSCs with product recovery and reuse. The model includes the number of core units with a nominal quality level that is disassembled, disposed, remanufactured and acquired in a given time period. The problem of consolidating returned end of life products in a CLSC was studied by Min et al. (2006), who proposed a mixed integer nonlinear programming model and a genetic algorithm for its solution. Yang et al. (2009) developed a model of a general CLSC network, which includes raw-material suppliers, manufacturers, retailers, customers, and recovery centers. Kannan et al. (2009) designed an integrated multi-echelon inventory distribution for closed-loop multi-echelon distribution inventory supply chain model for the make-to-order environment using genetic algorithm and particle swarm optimization. Kannan et al. (2010) proposed a multi-echelon, multi-period, multi-product CLSC network model for product return channels, in which decisions were made regarding material procurement, production, distribution, recycling, and disposal.

Bhattacharyya et al. (2014) and Shi et al. (2011) studied a production-planning problem for a multi-product closedloop system, in which the manufacturer has multiple channels for distribution: producing brand-new products and refurbishing returns into almost-new products. This study is similar to that of Kannan et al. (2010) and Özceylan et al. (2012), although this also considers the transfer of used products from the previous period to the next period, restricting our attention to swapping of strategies rather than material flow.

We propose a mixed integer programming model for designing the CLSC network. In the next phase, the results of the proposed model are used in sequential equation of game theory. The contributions of this paper to the literature are twofold: (1) multi-part mixed integer linear programming modelling with a multi-echelon inventory system and 
multi-period planning in a multi-product scenario of profit maximization and (2) analysis of realization time and/or delivery limits using the pay-off matrix of the sequential equation of game theory for each combination of strategies. The approach has the potential to help decision makers to be flexible in their decision-making processes.

\section{Problem Definition \& Modelling}

A CLSC model is proposed in which upstream and downstream flow of materials and their combined influence are considered simultaneously. The CLSC members are broadly classified into two groups: (1) forward chain facilities and (2) reverse chain facilities. The first group is used to purchase parts and to assemble them into products and deliver them to end users, whereas the second group is used for collecting, disassembling, servicing or discarding, extracting and dumping of the same products. The network is structured as a typical four-layer forward supply chain, with the following component: (1) four ancillary suppliers, (2) four assembly plants, (3) eight stores, and (4) five dealers. Similarly, a four-layer structure is considered for the reverse chain, that includes: (1) two collection yards, (2) three ELV dismantlers, (3) two service centers, (4) one trash yard for shredding and (5) one debris for dumping (Figure 1).

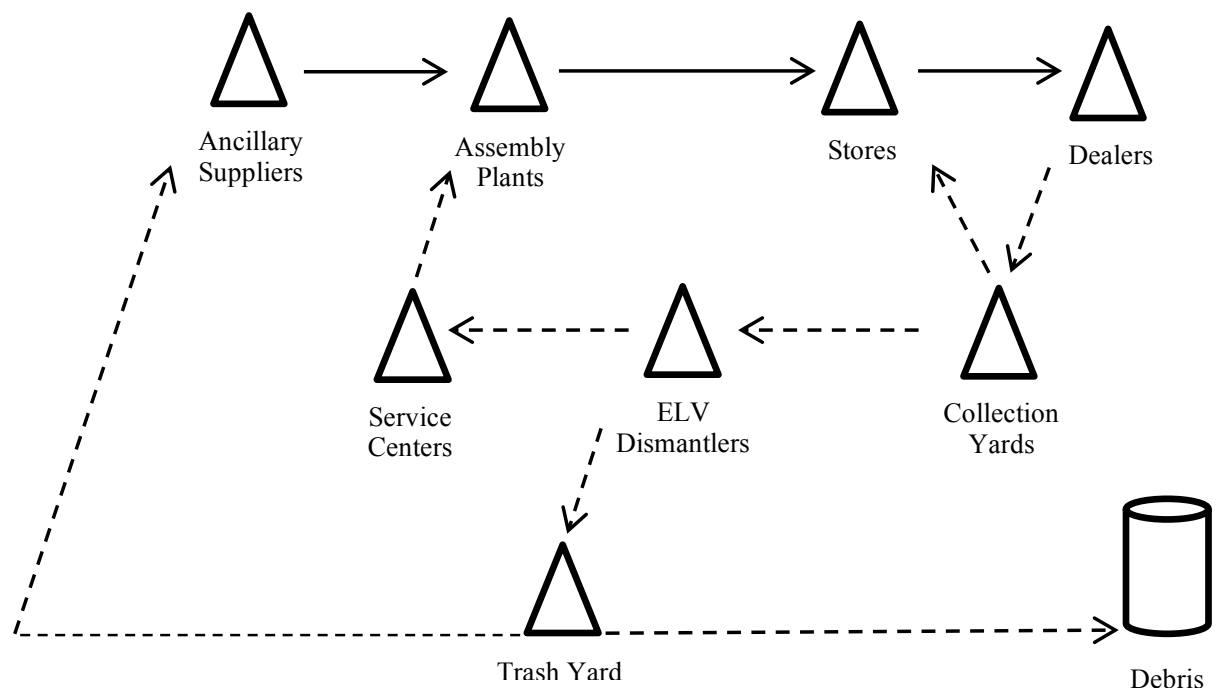

Fig 1: Proposed Closed Loop Supply Chain Network of Automobile Manufacturing System 
The network also includes multiple suppliers for the purpose of sourcing different parts for a certain number of plants in which the facilities cater to the same demand pattern. Purchased parts are assembled in assembly plants, and end products are transported to stores for crossdocking. The forward flow is complete when dealers receive the end product from a nearby store for merchandising. This network owns only one centrally co-ordinated service center dedicated for auto part refurbishment. The rest of the service centers are franchise operated and dedicated only for after sales servicing. For reasons of proximity, franchised service centers are a much better option for customers compared to a central service center. Here, demand is present at the dealer's level directly and that becomes both an exit point for a new product and an entry point for a used product. Shipment planning is therefore considered at the dealer place in the network.

The reverse flow starts when the used products are returned by customers and shipped from dealers to the collection yard. In this network, the used products are sent from various dealers' locations to the collection yard for two major reasons: (1) technical, such as defective parts or breakdown and (2) commercial, such as exchange offer or resale option for in-warranty claims or out-of-warranty service. Dealers' locations are divided into zones and each zone has a certain demand pattern. In the case of ELV return and resale, OEMs' production planning includes zone-wise collection rate and demand for information regarding used products. Used products acquired by different reintegration strategies i.e. "strategy of acquisition" based on warranty time (WRNT) and quality (QA), can create four possible states by a combination as follows: (1A) in warranty and in good condition, (2A) in warranty but in bad condition, (3A) out of warranty but in good condition and (4A) out of warranty and in bad condition. These used products in states $(2 \mathrm{~A}),(3 \mathrm{~A})$, and $(4 \mathrm{~A})$ can be transported to ELV dismantlers via collection yards for recycling, or if the used product is in state $(1 \mathrm{~A})$ and does not require any substantial processing, they can be directly shipped to stores after minor rework for resale. The products returned to the ELV dismantlers are inspected and discarded accordingly by "the reintegration strategy of acquisition", and classified and organized by "the reintegration strategy of conveyance." Products in states (2A), (3A), and (4A) are returned for disassembly, recycling, and / or refurbishing to make them reusable. Products except disassembled parts are sent to the trash yard for shredding. From the trash yard, ferrous metals and non - ferrous metals are obtained by the ancillary suppliers through "the reintegration strategy of cannibalisation" i.e. (1B) quantity-based acquisition (QNT) and (2B) deposit fee-based acquisition (DEP). Extracted raw material is then shipped to manufacture new parts at the facilities of ancillary 
producers and shredder fluff is sent for landfilling. Any thorough ELV take-back law or regulation introduced (Mohan 2014) to reduce extraction of raw material from natural resources would help OEMs to start a raw material recovery program and subsequently achieve stability and yield a profit in the long run. After the disassembly of a product, auto parts are cleaned and tested. This is similar to assembly lines, but not at quite such a high volume. The out-of-warranty and bad condition products or auto parts are sent to the disassembly line and transported onward to service centers. The servicing process is performed on the parts to bring them back to reusable condition. These 'almost-new' parts are transported to plants and used for manufacturing products in the next period.

The price of the product is mostly dependent on the reintegration strategy used in the network. Our research covers two types of product i.e. two variants of a passenger car, which are similar in terms of their components at each level (core, actual and augmented) and have limited variation in cost parameters (Kotlar, 1999). However, the model includes multiple product categories in terms of product lifecycle, i.e. new products and used products. Used products are further classified into two ranges: (1) recycled products and (2) non-recycled used products. Here, new products consume new parts, recycled products consume new parts and used parts, and non-recycled used products consume neither new nor used parts. There are two ways in which an enterprise can supply parts. The first is by purchasing the required parts from external suppliers, and the other is acquiring parts from secondary market by disassembling and overhauling the used products, which are in states $(2 \mathrm{~A}),(3 \mathrm{~A})$ and $(4 \mathrm{~A})$ for remanufacturing. Accordingly, the prices of new products, recycled products and non-recycled used products are different according to their demand.

The shipments of new recycled and non-recycled used products and/or spare parts of new and recycled products are transported from each facility to another facility so as to maximize the total profit through the ELV recovery program for the entire planning horizon of four periods. We have considered five kinds of cost: transportation, purchasing, processing, servicing, total inventory carrying cost and fixed costs for opening or closing of prospective ancillary suppliers, assembly plants and dealers where transportation cost changes with reintegration strategies of conveyance, i.e. (1C) centrally coordinated system (CCS), and (2C) third party coordinated system (3PL). Purchasing and processing cost changes with reintegration strategies of acquisition and cannibalisation, i.e. acquisition of products, which are (1A) under warranty and in good condition, (2A) under warranty but in bad 
condition, (3A) out-of-warranty but in good condition and (4A) out-of-warranty and in bad condition, and cannibalisation of parts on (1B) quantity-based and (2B) deposit fee-based. Parts are classified into three segments. The A Class covers expensive parts such as components of an engine, gear box, fuel injection system etc. The B Class covers moderately expensive parts, such as components of axel, differential, wheel etc. Finally, C Class covers inexpensive parts such as valuable materials or fluids. Figure 2 shows the mechanical operations involved in the ELV recovery process. Overall, each product consists of one unit of Part (A), three units of Part (B) and five units of Part (C). Part A requires ten units of ferrous metals, Part B requires two units of ferrous metals and five units of non-ferrous metals and Part C requires three units of non-ferrous metals.

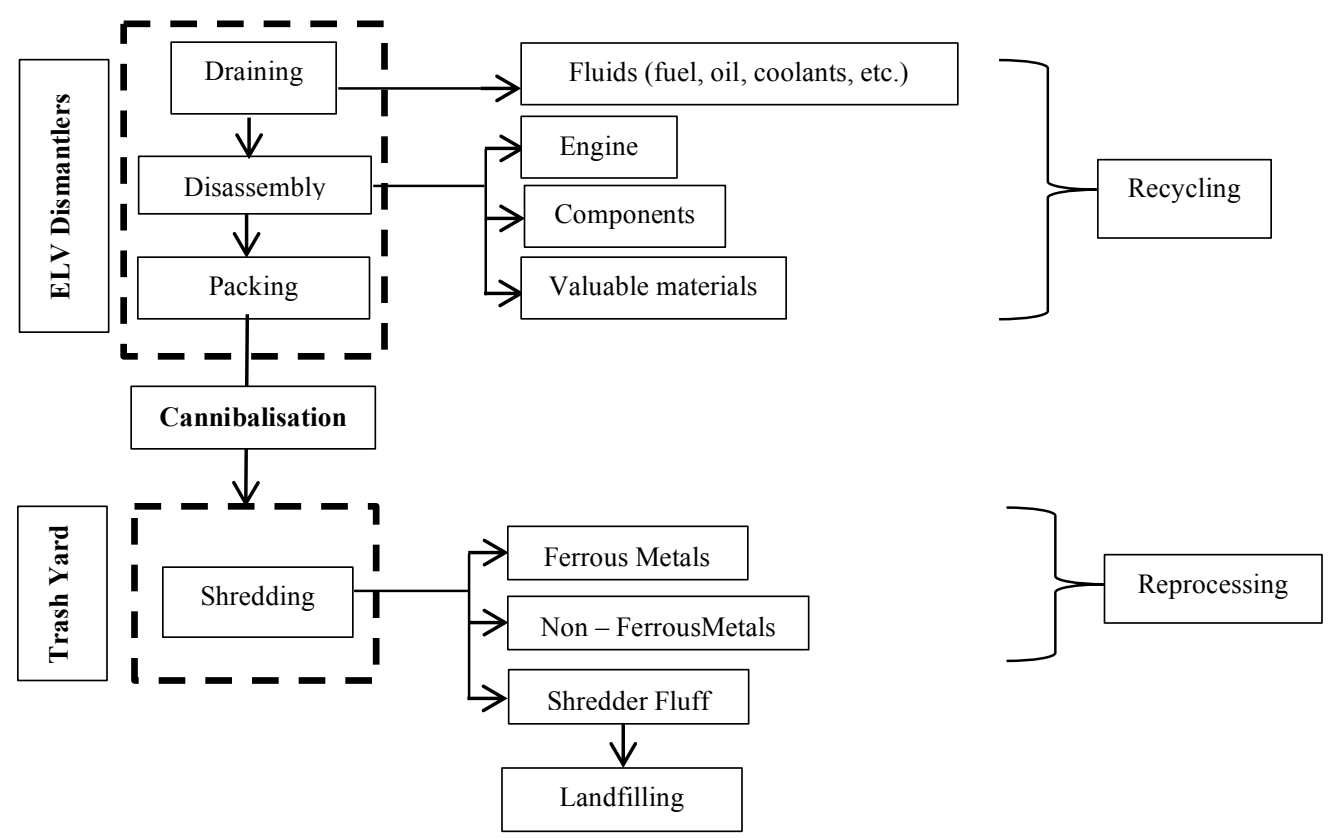

Fig 2: Simplified ELV Treatment Framework (Modified from Schultmann et al. 2005)

The combinations of cost determining strategies are (1D) CCS - WRNT - QNT, (2D) CCS - QA - QNT, (3D) CCS - WRNT - DEP, (4D) CCS - QA - DEP, (5D) 3PL - WRNT - QNT, (6D) 3PL - QA - QNT, (7D) 3PL - WRNT DEP, (8D) 3PL - QA - DEP for the supply chain. Strategies of acquisition and cannibalization are designated as strategies of recovery operations (RECOP) and the strategy of conveyance is designated under strategies of logistic operations (LOGOP) for the auto manufacturing enterprise. Decision makers, ' $M$ ' and 'N' do not know when they should switch strategies across the entire planning horizon. To address this issue, a mixed strategy non-zero sum game is designed where the players are decision makers ' $M$ ' and ' $N$ ' and they play a game by combining the strategies of RECOP and LOGOP. They also try to decide the best possible realization time of each strategy (RLTs) 
and/or delivery limits for the entire planning horizon. The probabilities or percentages, which are coming out from the game with no saddle point, are considered as RLTs and/or delivery limits. Pay-offs are simply the contribution margin derived from the mixed integer programming model for the discussed network, and calculated for all four periods with all possible strategic combinations. Both players are looking to maximize minimum profit or minimize maximum loss so essentially there is a common goal of maximizing the contribution margin. The objective of this simulation is to compute the equilibrium point of a finite-simultaneous game. Here, players cooperate in nature as they belong to the same supply chain and possess perfect information.

The problem is intensified by an additive price dependent demand function. Even though, the firm produces more than one brand, the study deals with only one of these. New products, used products and non - recycled used products of the same brand differ in quality status and warranty status and have different prices on the market. Here, the price dependent uncertain demand is represented by the additive form suggested by Jen - Ming Chen et al. (2011): $\Delta_{i}\left(\rho_{x}, \rho_{y}, \rho_{z}, \varepsilon_{i}\right)=\delta_{i}\left(\rho_{x}, \rho_{y}, \rho_{z}\right)+\varepsilon_{i}$, for $i=x, y$, and $z$ where, $\delta_{i}\left(\rho_{x}, \rho_{y}, \rho_{z}\right)$ and $\varepsilon_{i}$, are the mean demand and the random term of demand function $\Delta_{i}(\cdot)$, respectively. Here, $\rho_{1}, \rho_{2}, \rho_{3}$ are selling prices of new, recycled and non-recycled used products, respectively and $i$ is an integer. The random term $\varepsilon_{i}$, is on the range $\left[A_{i}, B_{i}\right]$, which constitutes maximum possible deviation from the mean demand $\delta_{i}\left(\rho_{x}, \rho_{y}, \rho_{z}\right)$. Let the cumulative distribution function and the probability density function of $\varepsilon_{i}$, be $\Phi_{i}(\cdot)$ and $\phi_{i}(\cdot)$, respectively. Likewise, let the mean and standard deviation of $\mathcal{E}_{i}$ be $\mu_{i}$ and $\sigma_{i}$, respectively. The mean demand $\delta_{i}\left(\rho_{x}, \rho_{y}, \rho_{z}\right)$ is price dependent and substitutable among new products, used products and non - recycled used products. The quantities of recovered core material from ELVs represent an input parameter and could be controlled by the firm solely using reintegration strategies of acquisition and cannibalization and are known as "endogenous" to the firm (Shi et al. 2011). Assumptions for the problem are as follows:

(1) The demand for each product is multi-period; uncertain, and must be fully satisfied (i.e. no shortages are allowed).

(2) The capacities of all facilities both forward and reverse are limited and fixed.

(3) All costs are deterministic and known as priori.

(4) Collection, dismantling and cannibalization rates are known. 
(5) No lead time is required for strategy implementation and no idle cost is involved for each of the strategies.

These assumptions are standard assumptions for supply chain design. Several studies such as Sheu et al. (2005), Neto et al. (2008), Wang and Hsu (2010) and Zceylan and Paksoy (2012) also considered these assumptions. The mixed integer mathematical model, with all the above-mentioned strategies and assumptions, and related formulations are presented as follows:

\section{Indices \& Sets}

$a$ Index for Ancillary supplier; $a \in A$

$b$ Index for Assembly plant; $b \in B$

$c$ Index for Store; $c \in C$

$d$ Index for Dealer; $d \in D$

$e$ Index for Collection yard; $e \in E$

$f$ Index for ELV dismantler; $f \in F$

$g \quad$ Index for Service centre; $g \in G$

$O$ Index for Trash yard; $O \in O$

$h$ Index for Part; $h \in H$

$i \quad$ Index for Variant - based product category, $i \in I$

$j \quad$ Index for Lifecycle - based product category; $j \in J$

$k$ Index for Raw material; $k \in K$

$l \quad$ Index for Period; $l \in L$

$s \quad$ Index for Strategy; $s \in S$

\section{Decision Variables}

$A S T A P_{a b h l} \quad$ Shipment from Ancillary Supplier $a$ to Assembly Plant $b$ for Part $h$ in Period $l$

APTSbcjl Shipment from Assembly Plant $b$ to Store $c$ for Variant - based Product Category $i$ and Lifecycle based Product Type $j$ in Period $l$

$S T D_{c d j l} \quad$ Shipment from Store $c$ to Dealer $d$ for Product $j$ in Period $l$

$D T C Y_{d e l} \quad$ Shipment from Dealer $d$ to Collection Yard $e$ in Period $l$

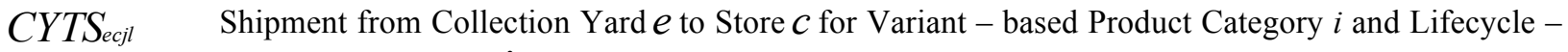
based Product Type $j$ in Period $l$

CYTED efjl Shipment from Collection Yard $e$ to ELV Dismantler $f$ Variant - based Product Category $i$ and Lifecycle - based Product Type $j$ in Period $l$

EDTTY fohl Shipment from ELV Dismantler $f$ to Trash Yard $\boldsymbol{o}$ for Part $h$ in Period $l$

EDTSCfghl Shipment from ELV Dismantlers $f$ to Service Centre $g$ for Part $h$ in Period $l$

TYTASoakl Shipment from Trash Yard $o$ to Ancillary Supplier $a$ for Raw material $k$ in Period $l$

TYTLF $F_{\text {okl }} \quad$ Shipment from Trash Yard $o$ to Debris for Raw material $k$ in Period $l$

SCTAPgbhl Shipment from Service Centre $g$ to Assembly Plant $b$ for Part $h$ in Period $l$

$B I N A S_{a l} \quad$ If Ancillary Supplier $a$ is utilised in period $l$ then 1 , otherwise, 0

$B I N A P b l \quad$ If Assembly Plant $b$ is utilised in period $l$ then 1 , otherwise, 0

$B I N S_{c l} \quad$ If Store $c$ is utilised in period $l$ then 1 , otherwise, 0

$U \quad$ Minimum Profit due to a set of strategies for Situation 'M' 


$\begin{array}{ll}V & \text { Maximum Loss due to a set of strategies for Situation ' } \mathrm{N} \text { ' } \\ \theta_{s} & \text { Possible RLTs and/or Delivery Limits for each strategy of ' } \mathrm{M} \text { ' } \\ \Phi_{s} & \text { Possible RLTs and/or Delivery Limits for each strategy of ' } \mathrm{N} \text { ' }\end{array}$

Parameters

(Wherever there is a cost parameter the unit is INR (1 USD $\approx 64$ INR))

CAPSAP $_{a h l} \quad$ Capacity of Ancillary Supplier $a$ for Part $h$ in Period $l$ (Unit Items)

CAPPLNT $\quad$ Capacity of Assembly Plant $b$ for Part $h$ in Period $l$ (Unit Items)

CAPSTOR $_{a h l} \quad$ Capacity of Sore $c$ for Part $h$ in Period $l$ (Unit Items)

$D E M D E L_{d l} \quad$ Demand of Dealer $d$ in Period $l$ (Unit Items)

$C A P C O L Y_{e l} \quad$ Capacity of Collection Yard $e$ in Period $l$ (Unit Items)

CAPELVD $D_{f h l} \quad$ Capacity of to ELV Dismantler $f$ for Part $h$ in Period $l$ (Unit Items)

CAPSERC $C_{a h l} \quad$ Capacity of Service Centre $g$ for Part $h$ in Period $l$ (Unit Items)

$C_{\text {APTRY }} \quad$ Caplacity of Trash Yard $O$ for Raw material $k$ in Period $l$ (ton)

TRANSCOST $T_{a b}$ Transportation Cost for shipping from Ancillary Supplier $a$ to Assembly Plant $b$ (INR /Unit Item*km)

TRANSCOST $_{b c}$ Transportation Cost for shipping from Assembly Plant $b$ to Store $c$ (INR/Unit Item*km)

TRANSCOST $T_{c d}$ Transportation Cost for shipping from Store $c$ to Dealer $d$ (INR/Unit Item*km)

TRANSCOST $_{d e}$ Transportation Cost for shipping from Dealer $d$ to Collection Yard $e$ (INR/Unit Item*km)

TRANSCOST $_{e c}$ Transportation Cost for shipping from Collection Yard $e$ to Store $c$ (INR/Unit Item*km)

TRANSCOST $_{\text {ef }}$ Transportation Cost for shipping from Collection Yard $e$ to ELV Dismantler $f$ (INR/Unit Item* $\mathrm{km}$ )

TRANSCOST $_{f g}$ Transportation Cost for shipping from ELV Dismantler $f$ to Service Centre $g$ (INR/Unit Item* $\mathrm{km}$ )

$\operatorname{TRANSCOST}_{g b}$ Transportation Cost for shipping from Service Centre $g$ to Assembly Plant $b$ (INR /Unit Item*km)

$\operatorname{TRANSCOST}_{f o} \quad$ Transportation Cost for shipping from ELV Dismantler $f$ to Trash Yard $\boldsymbol{O}$ (INR/Unit Item*km)

TRANSCOST

TRANSCOST $_{o k}$ Transportation Cost for shipping from Trash Yard $O$ to Debris (INR $/ \mathrm{kg} * \mathrm{~km}$ )

$\tau$ Th

$\tau_{k}$

Yal

$\gamma b l$

$\gamma d l$

$\mathrm{H} l$

$\pi i j$

$\pi i j h$

$\pi_{i j k}$

$\varphi$ ih

$\varphi_{i k}$

$\psi_{i j}$

$v_{s}$

$\lambda_{s}$

$\mathfrak{R}_{s}$

$\omega_{s}$

$\eta_{s}$

$\kappa a$
Number of part $h$ cannibalized from disassembling of one unit of product

Amount of raw material $k$ extracted from shredding of one unit of product

Costs of utilisation for prospective Ancillary Suppliers $a$ in period $l$ (INR)

Costs of utilisation for prospective Assembly Plants $b$ in period $l$ (INR)

Costs of utilisation for prospective Dealers $d$ in period $l$ (INR)

Unit cost of holding (INR/kg*week)

Unit cost of purchasing product category $i$ type $j$ (INR/Unit Item)

Unit cost of purchasing part $h$ (INR/Unit Item)

Unit cost of purchasing raw material $k(\mathrm{INR} / \mathrm{kg})$

Unit cost of processing part $h$ (INR/Unit Item)

Unit cost of processing raw material $k(\mathrm{INR} / \mathrm{kg})$

Unit cost of discarding product category $i$ type $j$ (INR/Unit Item)

Percentage of demand, which is collected by collection centres (\%)

Percentage of collected amount, which is re-sent to assembly plants (\%)

Percentage of collected amount, which is re-sent to stores (\%)

Percentage of collected amount, which is re-sent to ancillary suppliers (\%)

Percentage of shredded amount, which is disposed for land-filling to debris (\%)

Maximum available number of Ancillary plants $a$ in period $l$ 
In the first stage, the parameters include all retail prices and direct costs; hence the objective function $\Gamma_{s}$ represents the overall contribution margin.

Objective Function

Maximize: $\Gamma_{s}=$

$\sum_{i} \sum_{j} \mathrm{P}_{i j} \cdot \delta_{i}\left(\rho_{x}, \rho_{y}, \rho_{z}\right)-\sum_{a} \sum_{b} \sum_{i} \sum_{j} \sum_{k} \sum_{h} \sum_{l} A S T A P a b h l \cdot\left(\right.$ TRANSCOSTab $\left.+\mathrm{H}_{l}+\pi_{i j k}+\varphi_{i k}\right)+$

$\sum_{b} \sum_{c} \sum_{i} A P T S b c j l_{b} \cdot\left(\operatorname{TRANSCOST}_{b c}+\mathrm{H}_{l}\right)+\sum_{c} \sum_{d} \sum_{i} \operatorname{STD}_{c d j l} \cdot\left(\operatorname{TRANSCOST}_{b c}+\mathrm{H}_{l}\right)+$

$\sum_{d} \sum_{e} \sum_{i} D_{T C Y} T_{d e l} \cdot\left(\right.$ TRANSCOST $\left._{d e}+\mathrm{H}_{l}+\pi_{i j}+\pi_{i j h}\right)+\sum_{e} \sum_{c} \sum_{i} C_{i}$ TSSecl $_{e} \cdot\left(\right.$ TRANSCOST $\left._{e c}+\mathrm{H}_{l}\right)+$

$\sum_{e} \sum_{f} \sum_{i}$ CYTED $_{e f j l} \cdot\left(\right.$ TRANSCOST $\left._{e f}+\mathrm{H}_{l}+\varphi_{i h}\right)+\sum_{f} \sum_{g} \sum_{i}$ EDTSC $f g h l_{i} \cdot\left(\operatorname{TRANSCOST}_{f g}+\mathrm{H} l+\psi_{i j}\right)+$ $\sum_{f} \sum_{o} \sum_{i} \operatorname{EDTTY}_{\text {fohl }} \cdot\left(\operatorname{TRANSCOST}_{f o}+\mathrm{H}_{l}+\varphi_{i k}\right)+\sum_{o} \sum_{a} \sum_{i} \operatorname{TYTAS}_{\text {oakl }} \cdot\left(\right.$ TRANSCOSToa $\left.+\mathrm{H} l+\varphi_{i k}\right)+$ $\sum_{g} \sum_{b} \sum_{i} S C C T A P g b h l_{1} \cdot\left(\right.$ TRANSCOST $\left._{g b}+\mathrm{H}_{l}+\varphi_{i h}\right)+\sum_{k}$ TYTLF $_{o k l} \cdot($ TRANSCOSTok $)+$ $\sum_{a} \sum_{l} \kappa a \cdot \gamma_{a l}+\sum_{b} \sum_{l} \kappa b \cdot \gamma_{b l}+\sum_{d} \sum_{l} \kappa d \cdot \gamma_{d l}$

The objective function value is the contribution margin or profit of the OEM with different sets of strategies, which has two generic components. The first one is revenue, which is calculated using price and demand of all (a) variantbased product category and (b) lifecycle-based product category. Second one is representing cost, which is the algebraic sum of quantity of shipments multiplied by transportation cost, holding cost, purchasing cost, processing cost and discarding cost respectively. Fixed cost associated with opening or closing of network facilities is added separately, as it is dependent on binary variables.

Constraints

$$
\begin{aligned}
& \sum_{a} \operatorname{ASTAP}_{a b h l}<\mathrm{CAPSAP}_{a h l}, \forall_{a, h, l} \\
& \sum_{b} \operatorname{APTS}_{b c j l}<C A P P L N T_{b l}, \forall_{b ; j ; l} \\
& \sum_{c} \operatorname{STD}_{c d j l}<C A P S T O R_{a h l}, \forall_{c ; j} \\
& \sum_{d} \operatorname{DTCY}_{d e l}<\tau_{h} \cdot D E M D E L_{d l}<\tau_{k} \cdot D E M D E L_{d l}, \forall_{i ; j ; l}
\end{aligned}
$$




$$
\begin{aligned}
& \sum_{c} C Y T S_{e c j l}+\sum_{f} C Y T E D_{e f j l}<C A P C O L Y_{e l}, \forall_{e ; c ; f} \\
& \sum_{h} \operatorname{EDTTY}_{\text {fohl }}+\sum_{g} \operatorname{EDTSC}_{\text {fghl }}<C A P E L V D_{f h l}, \forall_{g ; h} \\
& \sum_{b} S C T A P_{g b h l}<C A P S E R C_{a h l}, \forall_{b ; h} \\
& \sum_{a} T Y T A S_{\text {oakl }}+\sum_{l} T Y T L F_{o k l}<C A P T R Y_{a k l}, \forall_{a ; k ; l} \\
& \sum_{k} A_{S T A P_{a b h l}}+\sum_{k} \text { TYTAS }_{\text {oak }}=\sum_{i} \sum_{j} \text { APTS }_{b c j l}, \forall_{k ; h ; l} \\
& \sum_{b} A P T S_{b c j l}-\sum_{c} S T D_{c d j}=0, \forall_{i ; j} \\
& v_{s} \cdot \sum_{x i c} S T D_{c d j}-\sum_{d} D T C Y_{d e l}=0, \forall_{c ; d} \\
& \sum_{d} D T C Y_{d e l}+\sum_{e} C Y T E D_{e f j l}+\tau_{h} \cdot \sum_{f} E D T S C_{f g h l}+\sum_{g} S C T A P_{g b h l}=\left(1-\lambda_{s}\right) \cdot \sum_{b} A P T S_{b c j l}, \forall_{d ; e ; f ; g} \\
& \sum_{i} \sum_{j} \sum_{e} C Y T S_{e c j l}+\left(1-\mathfrak{R}_{s}\right) \cdot S T D_{c d j l}<\tau_{h} \cdot D E M D E L_{d l}<\tau_{k} \cdot D E M D E L_{d l}, \forall_{i ; j, l} \\
& \sum_{h} \sum_{l} E D T T Y_{\text {fohl }}+\tau_{k} \cdot\left(1-\eta_{s}\right) \cdot \sum_{k} \sum_{l} \operatorname{TYTAS}_{\text {oakl }}=\left(1-\omega_{s}\right) \cdot \sum_{k} \sum_{l} A S T A P_{a b h}, \forall_{h ; i ; j ; k ; l} \\
& B I N A S_{a l}, B I N A P_{b l}, B I N S_{c l}=\{0,1\}, \forall_{a ; b ; c ; l} \\
& A S T A P_{a b h}, A_{P T S_{b c j l},}, S T D_{c d j l}, D T C Y_{d e l}, C Y T S_{e c j l} \geq 0, \forall_{a ; b ; c ; d ; e ; h ; j ; l} \\
& \text { CYTED }_{\text {effl }}, \text { EDTTY }_{\text {fohl }}, \text { EDTSC }_{\text {fghl }}, S C T A P_{\text {gbh }}, \text { TYTAS }_{\text {oakl }}, \text { TYTLF }_{\text {okl }} \geq 0, \forall_{a ; b ; e ; f ; g ; h ; j ; k ; l ; o}
\end{aligned}
$$

Here, constraints from (i) to (viii) ensures that the production and transportation amount must not go beyond the capacity of all network facilities from extreme upstream i.e. ancillary supplier to extreme downstream i.e. trash yard. Constraint (ix) is balancing forward shipment quantity and shipment of ELVs. Constraints from (xi) to (xiv) ensure that demands of each categories and types of product must fully be met with best (cost effective) possible combination of manufacturing and re-manufacturing. Constraint $(x v)$ represents binary variables and last two (xvi) and (xvii) signify non-negativity of constraints.

Now in the next stage of this modelling, we have introduced the simultaneous equation. The objective function value of $\Gamma_{s}$ is the overall contribution margin or profit generated from the whole supply chain management in the proposed closed loop network. Here, the value of $\Gamma_{s}$ is used as a payoff value for the simultaneous game. Constraint (xviii) and (xx) specify that a total aggregated contribution margin generated from each strategy should be greater than $\boldsymbol{U}$ i.e. minimum profit of Player $\mathbf{M}$ and less than $\boldsymbol{V}$ i.e. maximum loss for Player $\mathbf{N}$ respectively. Lastly, 
constraint (xix) and (xxi) ensures that the summation of all possible RLTs and/or Delivery Limits is $100 \%$ or 1 for each strategy of player $\mathbf{M}$ and $\mathbf{N}$ respectively.

Objective functions

Maximize : $U$

Minimize : $V$ s.t.

s.t.

Constraints

$$
\begin{aligned}
& U \leq \sum_{s} \Gamma_{s} \cdot \theta_{s} \\
& \sum_{s} \theta_{s}=1 \\
& V \geq \sum_{s} \Gamma_{s} \cdot \Phi_{s} \\
& \sum_{s} \Phi_{s}=1
\end{aligned}
$$

Once again we used mixed integer linear programming to solve the payoff matrix. As a result, we found the percentages of $\theta_{s}$ and $\Phi_{s}$, which are final outcomes of the model in a form of RLTs and/or Delivery Limits. Thus, OEM could figure out that how much RLT and/or delivery limits be allocated for individual strategies. RECOP and LOGOP strategies are interchanged after certain RLT and/or delivery limits in a planning horizon.

\section{Computational Experience}

In this section, the results obtained from the proposed model are presented using a realistic CLSC network problem. Instances are produced, based on randomly generated parameters, to illustrate the properties of the problem and to derive insights. It is important to mention that our interest does not lie in studying the computational properties of the model, or investigating the complexities in solving the problem, but rather in providing insights on the effects of the changes in various parameters of the problem on a number of performance measures, defined below. We then derive some managerial insights for different scenarios.

Data Description:

OEM: An Indian Automobile Manufacturer.

Product: Passenger Cars

Periods $=4$, where each period consists of three calendar months.

Warranty $=2$ years

Cost of Materials (Ferrous and Non-Ferrous) $\cong 13062.75$ INR and 1612.50 INR per car 
Holding Cost $\cong 20 \%$ of the unit price

Price $($ VAR 1, VAR 2) $\cong 2,94,509 \mathrm{INR}, 3,18,098 \mathrm{INR}$

(Source: Society of Indian Automotive Manufacturing, 2010)

We considered four ancillary suppliers, four assembly plants and stores, five dealers, two collection yards, three ELV dismantlers, two service centres, one trash yard and two models of cars - VAR 1 and VAR 2. The product categories are (1) New vehicles, (2) Non - Recycled used vehicles and (3) Recycled vehicles.

Strategies used for Simultaneous Equation are:

A. LOGOP:

(1) Reintegration strategies of conveyance effecting Transportation cost-

I. Centrally Coordinated System $(\mathrm{CCS}) \cong 1.7$ INR per Ton-Km

II. Fourth party Coordinated System $(3 \mathrm{PL}) \cong 1.5 \mathrm{INR}$ per Ton-Km

(Source: Clell Harral et. al 2003)

The unit transportation costs are calculated based on operating costs that are correlated with the amount of service provided, and include costs of fuel, salaries, wages, operating supplies, insurance, and depreciation (Forkenbrock 2001).

B. RECOP:

(2) Reintegration strategies of acquisition effecting purchasing cost-

I. Products(VAR 1, VAR 2) in warranty and in good condition $\cong 2,76,415$ INR; 3,06,000 INR at New Delhi

II. Products(VAR 1, VAR 2) in warranty but in bad condition $\cong 1,21,161 \mathrm{INR} ; 2,11,000 \mathrm{INR}$ at New Delhi

III. Products(VAR 1, VAR 2) out of warranty but in good condition $\cong 54,384$ INR; 78,197 INR at New Delhi

IV. Products(VAR 1, VAR 2) out of warranty and in bad condition $\cong 23,970$ INR; 38,954 INR at New Delhi

(Source: Vikram Shende 2014, Official website of Maruti Suzuki India Limited)

(3) Reintegration strategies of Cannibalization effecting Purchasing Cost-

I. Parts (A Class, B class, C Class) on Quantity Based $\cong 19,324$ INR (20 units of component i.e. engine, gear box, fuel injection system etc.); 7,3254 INR (60 units of component i.e. axel, differential, wheel etc.); 3759 INR (80 units of valuable materials or Fluids)

II. Parts (A Class, B Class, C Class) on Deposit Fee Based $\cong 8,458$ INR (Extended incentive scheme for 3 years), 6165 INR (Extended incentive scheme for 2 years), 3290 INR (Extended incentive scheme for 1years) 


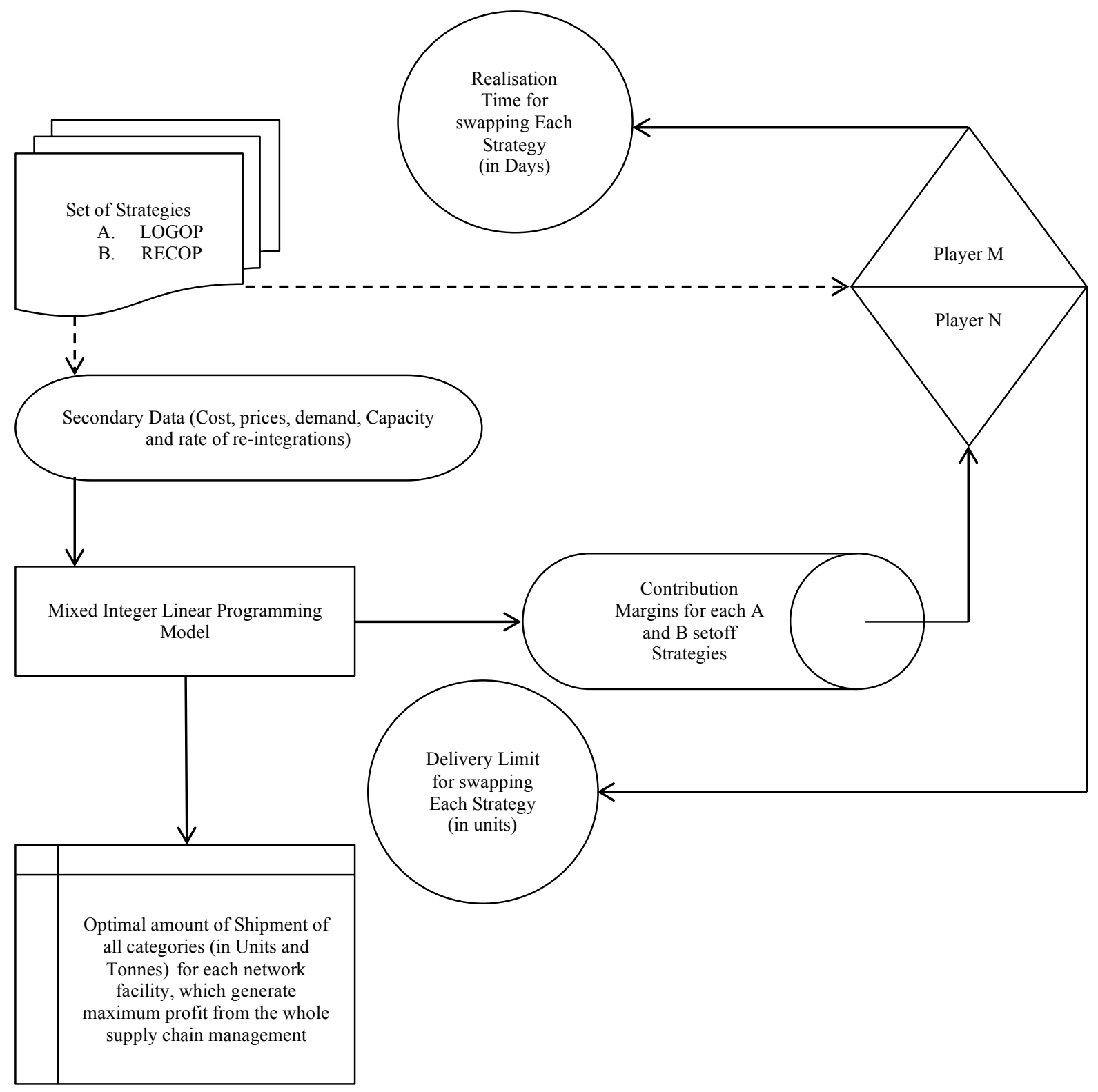

Fig 3: Explaining solution procedure through research flowchart 
Table 1: Demand Data for VAR 1

\begin{tabular}{|c|c|c|c|c|c|c|c|c|c|c|c|c|c|c|c|}
\hline \multicolumn{2}{|c|}{ ECONOMY SEGMENT } & YEAR & April & May & June & Jul & August & September & October & November & December & January & February & March & Total \\
\hline \multirow[t]{15}{*}{ VAR 1} & New Vehicles & $2009-10$ & 2345 & 2336 & 2438 & 2796 & 2734 & 3207 & 3124 & 3040 & 2574 & 2494 & 3178 & 2762 & 33028 \\
\hline & & 2010-11 & 2258 & 2558 & 2090 & 1680 & 1919 & 1608 & 2631 & 2440 & 1798 & 1876 & 2712 & 2915 & 26485 \\
\hline & & 2011-12 & 2528 & 2262 & 1823 & 1646 & 1813 & 1993 & 1601 & 1373 & 1621 & 2114 & 2193 & 2286 & 23253 \\
\hline & & $2012-13$ & 1705 & 1222 & 1463 & 1411 & 1382 & 1414 & 1438 & 1101 & 1246 & 1635 & 1680 & 2136 & 17833 \\
\hline & Total 19305 for 4 periods & 2013-14 & 1680 & 1626 & 1336 & 1662 & 1522 & 1594 & 2087 & & & & & & 11507 \\
\hline & Non-Recycled Vehicles & $2009-10$ & 657 & 654 & 683 & 783 & 766 & 898 & 875 & 851 & 721 & 698 & 890 & 773 & 9248 \\
\hline & & 2010-11 & 632 & 716 & 585 & 470 & 537 & 450 & 737 & 683 & 503 & 525 & 759 & 816 & 7416 \\
\hline & & 2011-12 & 708 & 633 & 510 & 461 & 508 & 558 & 448 & 384 & 454 & 592 & 614 & 640 & 6511 \\
\hline & & $2012-13$ & 477 & 342 & 410 & 395 & 387 & 396 & 403 & 308 & 349 & 458 & 470 & 598 & 4993 \\
\hline & Total 5405 for 4 periods & 2013-14 & 470 & 455 & 374 & 465 & 426 & 446 & 584 & & & & & & 3222 \\
\hline & Recycled Vehicles & $2009-10$ & 305 & 304 & 317 & 363 & 355 & 417 & 406 & 395 & 335 & 324 & 413 & 359 & 4294 \\
\hline & & $2010-11$ & 294 & 333 & 272 & 218 & 249 & 209 & 342 & 317 & 234 & 244 & 353 & 379 & 3443 \\
\hline & & 2011-12 & 329 & 294 & 237 & 214 & 236 & 259 & 208 & 178 & 211 & 275 & 285 & 297 & 3023 \\
\hline & & $2012-13$ & 222 & 159 & 190 & 183 & 180 & 184 & 187 & 143 & 162 & 213 & 218 & 278 & 2318 \\
\hline & Total 2510 for 4 periods & 2013-14 & 218 & 211 & 174 & 216 & 198 & 207 & 271 & & & & & & 1496 \\
\hline
\end{tabular}


Table 2: Demand Data for VAR 2:

\begin{tabular}{|c|c|c|c|c|c|c|c|c|c|c|c|c|c|c|c|}
\hline \multicolumn{2}{|c|}{ ECONOMY SEGMENT } & \multirow{2}{*}{$\begin{array}{l}\text { YEAR } \\
2009-10\end{array}$} & \multirow{2}{*}{$\begin{array}{l}\text { April } \\
20358\end{array}$} & \multirow{2}{*}{$\begin{array}{l}\text { May } \\
19538\end{array}$} & \multirow{2}{*}{$\begin{array}{l}\text { June } \\
17977\end{array}$} & \multirow{2}{*}{$\begin{array}{c}\text { Jul } \\
17294\end{array}$} & \multirow{2}{*}{$\begin{array}{c}\begin{array}{c}\text { Augu } \\
\text { st }\end{array} \\
21829\end{array}$} & \multirow{2}{*}{$\begin{array}{c}\text { September } \\
20045\end{array}$} & \multirow{2}{*}{$\begin{array}{l}\text { Oct } \\
18877\end{array}$} & \multirow{2}{*}{$\begin{array}{l}\text { Nov } \\
22012\end{array}$} & \multirow{2}{*}{$\begin{array}{c}\text { Dec } \\
18974\end{array}$} & \multirow{2}{*}{$\begin{array}{c}\text { Jan } \\
21067\end{array}$} & \multirow{2}{*}{$\begin{array}{c}\text { Feb } \\
20844\end{array}$} & \multirow{2}{*}{$\begin{array}{l}\text { March } \\
16397\end{array}$} & \multirow{2}{*}{\begin{tabular}{|c|} 
Total \\
235212
\end{tabular}} \\
\hline VAR 2 & New Vehicles & & & & & & & & & & & & & & \\
\hline & & $2010-11$ & 19168 & 25340 & 19992 & 27639 & 28430 & 30147 & 32612 & 32377 & 26937 & 33118 & 33015 & 38065 & 346840 \\
\hline & & $2011-12$ & 25462 & 25393 & 23240 & 24974 & 23170 & 21198 & 15197 & 24422 & 24113 & 32965 & 32909 & 35245 & 308288 \\
\hline & & $2012-13$ & 17842 & 20724 & 21645 & 17422 & 10488 & 21209 & 26600 & 23550 & 26234 & 28685 & 25030 & 27356 & 266785 \\
\hline & $\begin{array}{c}\text { Total } 268714 \text { for } 4 \\
\text { periods }\end{array}$ & 2013-14 & 19847 & 16411 & 20077 & 18206 & 17124 & 23620 & 22574 & & & & & & 137859 \\
\hline & \multirow{4}{*}{$\frac{\text { periods }}{\text { Non - Recycled Vehicles }}$} & $2009-10$ & 6515 & 6252 & 5753 & 5534 & 6985 & 6414 & 6041 & 7044 & 6072 & 6741 & 6670 & 5247 & 75268 \\
\hline & & $2010-11$ & 6134 & 8109 & 6397 & 8844 & 9098 & 9647 & 10436 & 10361 & 8620 & 10598 & 10565 & 12181 & 110989 \\
\hline & & $2011-12$ & 8148 & 8126 & 7437 & 7992 & 7414 & 6783 & 4863 & 7815 & 7716 & 10549 & 10531 & 11278 & 98652 \\
\hline & & $2012-13$ & 5709 & 6632 & 6926 & 5575 & 3356 & 6787 & 8512 & 7536 & 8395 & 9179 & 8010 & 8754 & 85371 \\
\hline & Total 85988 for 4 periods & 2013-14 & 6351 & 5252 & 6425 & 5826 & 5480 & 7558 & 7224 & & & & & & 44115 \\
\hline & \multirow[t]{4}{*}{ Recycled Vehicles } & $2009-10$ & 3461 & 3321 & 3056 & 2940 & 3711 & 3408 & 3209 & 3742 & 3226 & 3581 & 3543 & 2787 & 39986 \\
\hline & & $2010-11$ & 3259 & 4308 & 3399 & 4699 & 4833 & 5125 & 5544 & 5504 & 4579 & 5630 & 5613 & 6471 & 58963 \\
\hline & & 2011-12 & 4329 & 4317 & 3951 & 4246 & 3939 & 3604 & 2583 & 4152 & 4099 & 5604 & 5595 & 5992 & 52409 \\
\hline & & $2012-13$ & 3033 & 3523 & 3680 & 2962 & 1783 & 3606 & 4522 & 4004 & 4460 & 4876 & 4255 & 4651 & 45353 \\
\hline & Total 45681 for 4 periods & 2013-14 & 3374 & 2790 & 3413 & 3095 & 2911 & 4015 & 3838 & & & & & & 23436 \\
\hline
\end{tabular}


In 2013-14, the OEM of VAR1 and VAR2 generated a total profit after tax by sales and after sales services of 16351 Million INR by exporting 1, 27,379 units and sales in domestic market was 10, 06,316 units of Passenger cars till October 2014. So, each car gives them a PAT $\cong 14422.75$ INR and the processing cost of new cars (VAR1, VAR2) $\cong 2,65,420($ Class $\mathrm{A} \cong 1,15,654 \mathrm{INR} ;$ Class $\mathrm{B} \cong 95,050 \mathrm{INR} ; \mathrm{Class} \mathrm{C} \cong 54716 \mathrm{INR}) ; 2,89,000 \mathrm{INR}(\mathrm{Class} \mathrm{A} \cong$ 1,29,985 INR; Class $\mathrm{B} \cong 1,03,145 \mathrm{INR}$; Class $\mathrm{C} \cong 55,870 \mathrm{INR})$ and used cars (VAR1, VAR2) $\cong 2,39,325 \mathrm{INR}$ (Class $\mathrm{A} \cong 1,01,990 \mathrm{INR} ;$ Class $\mathrm{B} \cong 89,471 \mathrm{INR}$; Class $\mathrm{C} \cong 47,864 \mathrm{INR}) ; 2,41,065 \mathrm{INR}(\mathrm{Class} \mathrm{A} \cong 1,02,681$ $\mathrm{INR}$; Class $\mathrm{B} \cong 90,211 \mathrm{INR}$; Class $\mathrm{C} \cong 48,173 \mathrm{INR})$ per car for assembling and dismantling consecutively where both include marketing, distribution, overhead cost, cost of capital, power, water, technology set up, facilities, salvage and R\&D (Schultmann et. al 2006). Overall discarding cost for VAR 1 and VAR 2 is 13,500 INR; 15,700 INR per car respectively. In addition to that, the costs of opening and closing are found to be $3,06,275$ INR ( $\gamma a l$ ), 1 , 83,765 INR $(\gamma b l)$ and 1, 10,259 INR $(\gamma d l)$ for each ancillary supplier, assembly plant, dealer in all periods, respectively (Source: Vikram Shende 2014, Official website of Maruti Suzuki India Limited). Other parameters are set as follows $\kappa a, \kappa b$ and $\kappa d: 4$ (Rana et. al 2013). The mixed integer linear programming formulation of the sample network contains 488 variables and 975 constraints. All computational experiments are conducted on a PC with an Intel Xeon $3.16 \mathrm{GHz}$ processor with $1 \mathrm{~GB}$ of RAM, and the computation time required in solving the model to optimality using the LINGO software. Table (3) refers the payoff matrix for the sequential form of equation where, objective function value i.e. contribution margins or profit are considered as pay off and percentages or probabilities are considered as realisation time and / or delivery limits for each strategy. 
Table 3: Payoff Matrix (Contribution Margins in thousands)

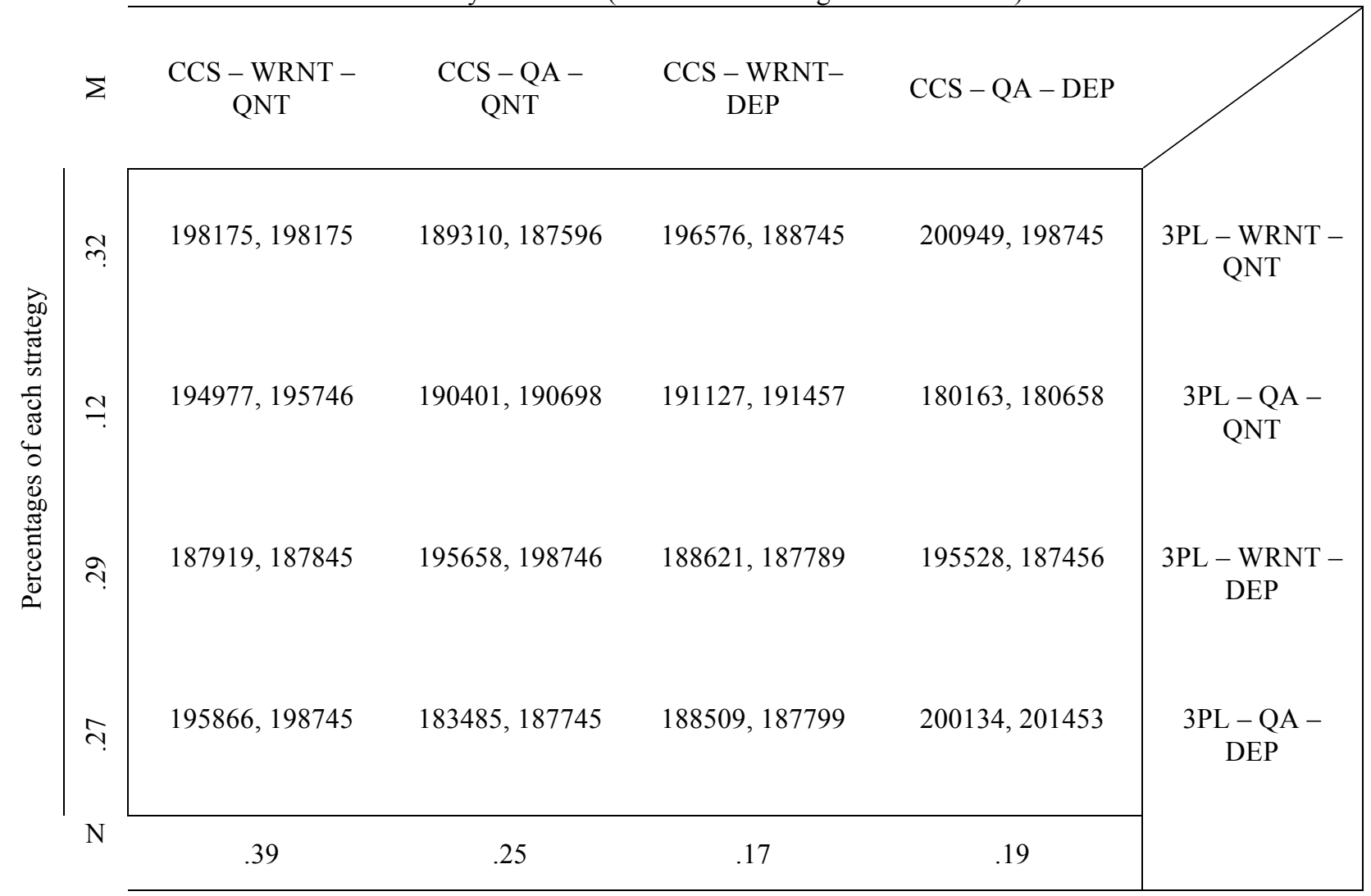

Now, the percentages of occurrence for each strategy came out from the sequential equation where 1 or 100 is scaled as the total length of planning horizon (four periods) i.e. 365 days. Subsequently, percentages are multiplied by that 1 or 100 scale of 365 days to compute the number of days for allocation of respective strategy. In another dimension of this model, OEM could change its strategies not only in accordance with time; but also with delivery limits. Same scale and percentages are multiplied by the demand data of each product segment to calculate delivery limits. Thus, delivery limit is used for indication of strategic changes, which is a more refined and concreate way of sending signal to OEM for swapping strategies (Table 4). Here, the change in demand is updated continuously to compute the payoff for all periods. Delivery limit of Table 4 could indicate strategic change in CLSC to the players M and N of OEM. Swapping strategies according to realized demands increase profit. The most cumbersome aspect of this model is performing multiple simulations in different combinations of strategies. Each objective function value is computed using different set of strategies. Set up of input parameters are varied as per the combination of strategies. In order to fill up the whole payoff matrix we had to compute all 32 possible objective function values with all 32 sets of input parameters for 8 sets of combined strategies. 
Table 4: Realization times for all four periods of the planning horizon and delivery limit for swapping strategies.

\begin{tabular}{l|ccccccccc} 
& \multicolumn{1}{c}{ Delivery Limit } \\
\cline { 2 - 9 } & RLTS & Days allocated to Strategies & A1 & A2 & A3 & B1 & B2 & B3 \\
\cline { 2 - 9 } 3PC - WRNT - QNT & 0.32 & 116.8 & 6178 & 1730 & 803 & 85988 & 27516 & 14618 \\
3PC - QA - QNT & 0.12 & 43.8 & 2317 & 649 & 301 & 32246 & 10319 & 5482 \\
3PC - WRNT - DEP & 0.29 & 105.85 & 5598 & 1568 & 728 & 77927 & 24937 & 13248 \\
3PC - QA - DEP & 0.27 & 98.55 & 5212 & 1459 & 678 & 72553 & 23217 & 12334 \\
CCS - WRNT - QNT & 0.39 & 142.35 & 7529 & 2108 & 979 & 104798 & 33536 & 17816 \\
CCS - QA - QNT & 0.25 & 91.25 & 4826 & 1351 & 627 & 67179 & 21497 & 11420 \\
CCS - WRNT- DEP & 0.17 & 62.05 & 3282 & 919 & 427 & 45681 & 14618 & 7766 \\
CCS - QA - DEP & 0.19 & 69.35 & 3668 & 1027 & 477 & 51056 & 16338 & 8679 \\
\hline
\end{tabular}

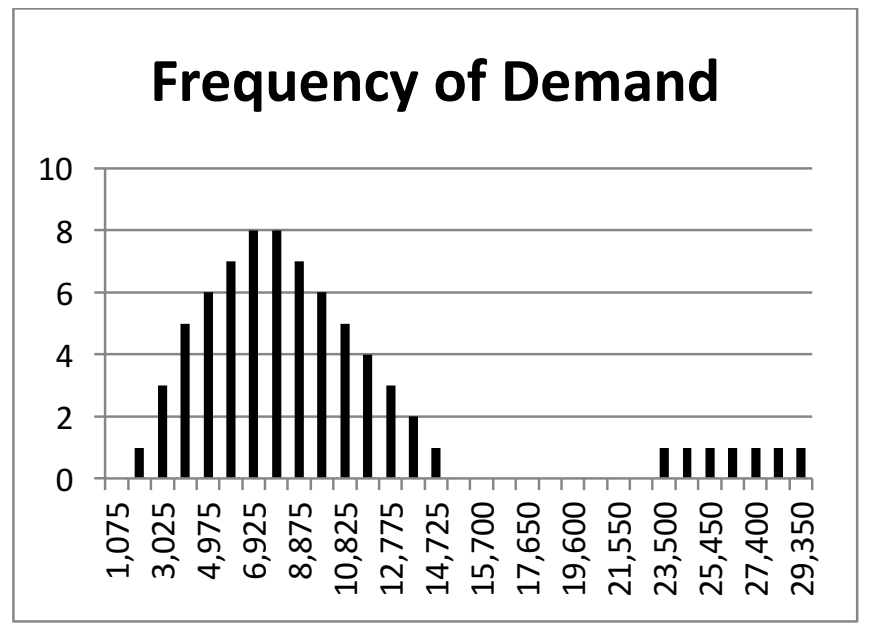

Fig 4: Overall Demand Pattern for the OEM.

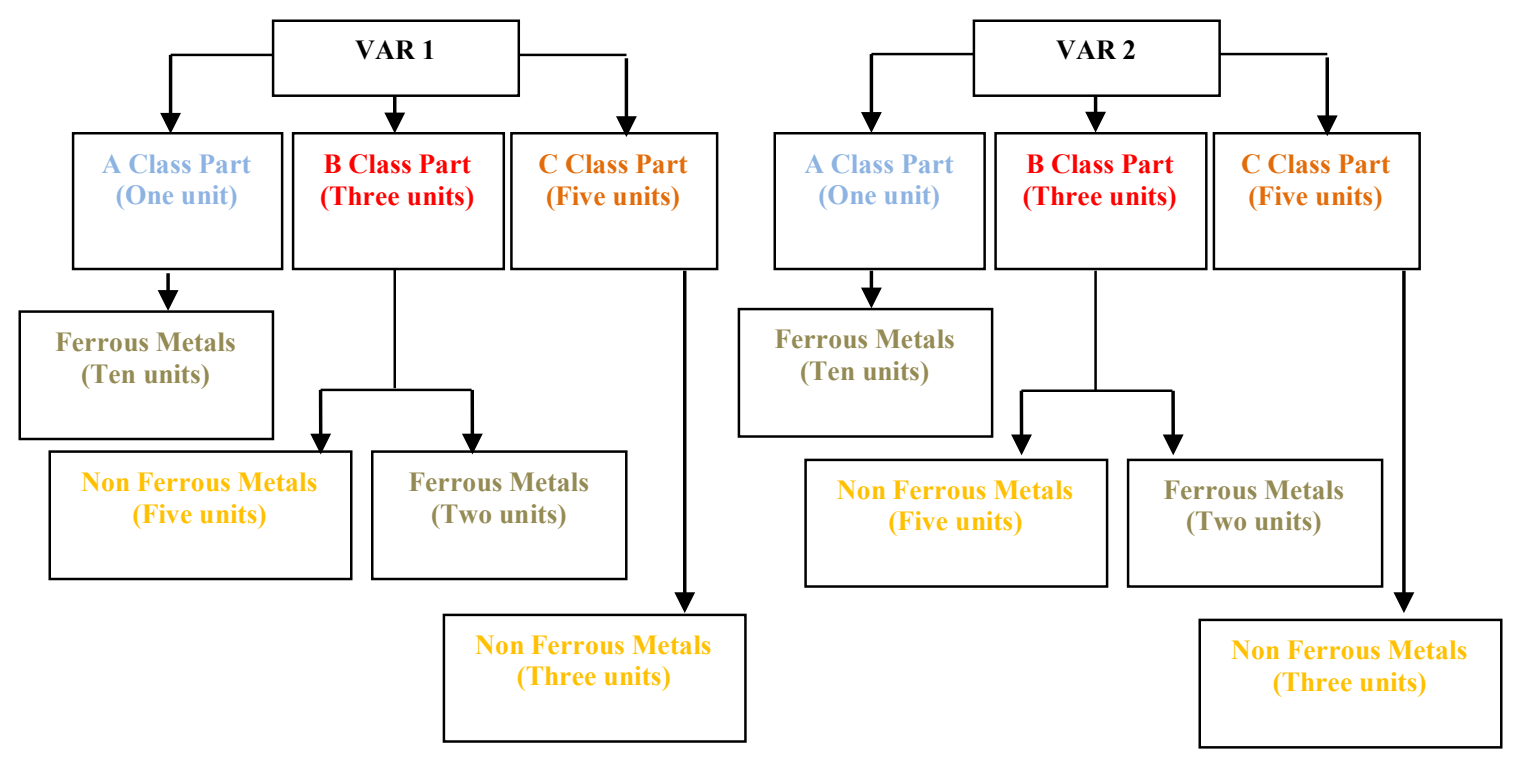

Fig 5: Bill of Material of End Product. 


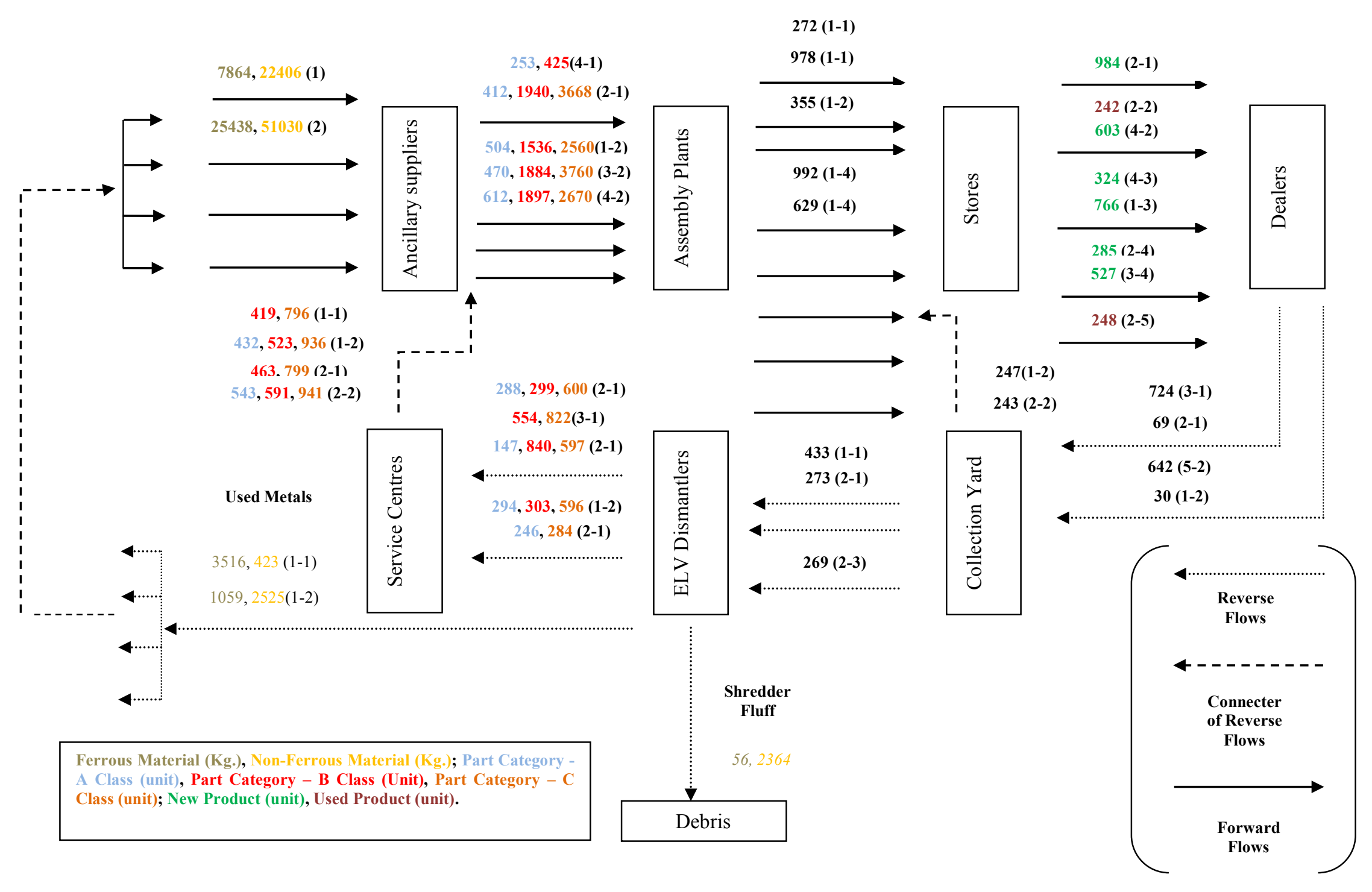

Fig 6: Optimal Flow at first period. 
Table 5: Scenario Analysis of Performance in Contribution Margin (PCM):

\begin{tabular}{|c|c|c|c|}
\hline \multirow[b]{2}{*}{ Sr. No. } & \multirow[b]{2}{*}{ Performance Criteria } & \multicolumn{2}{|l|}{ Profit is hundreds and Costs are in Ten thousands } \\
\hline & & Units; Rates and Value & Profit by Strategy 1D (INR) \\
\hline PCM1 & Total Objective Function Value & from the sales of two items INR & 198175.3 \\
\hline PCM2 & Transportation Costs & $1.7 ; 1.5$ INR per Ton-Km & 732.03 \\
\hline PCM3 & Purchasing Cost of VAR 1 car & $2,76,415 ; 1,21,161 ; 54,384 ; 23,970$ INR per car at New Delhi & 1054.52 \\
\hline PCM4 & Purchasing Cost of VAR 2 car & $3,06,000 ; 2,11,000 ; 78,197 ; 38,954$ INR per car at New Delhi & 1192.63 \\
\hline PCM5 & Purchasing Cost of Parts A & 19,$324 ; 8,458$ INR per 20 units; scheme for 3 years & 236.19 \\
\hline PCM6 & Purchasing Cost of Parts B & 7,$3254 ; 6165$ INR per 60 units; scheme for 2 years & 173.46 \\
\hline PCM7 & Purchasing Cost of Parts C & $3759 ; 3290$ INR per 80 units; scheme for 1 years & 94.65 \\
\hline PCM8 & Purchasing Cost of Material (Ferrous) & 13062.75 INR per car & 57.71 \\
\hline РCM9 & Purchasing Cost of Material (Non-Ferrous) & 13062.75 INR per car & 32.89 \\
\hline PCM10 & Processing of New Cars of VAR 1 & $2,65,420$ INR per car & 2015.19 \\
\hline PCM11 & Processing of New Cars of VAR 2 & $2,89,000 \mathrm{INR}$ per car & 2267.75 \\
\hline PCM12 & Processing of Used Cars VAR 1 & $2,39,325$ INR per car & 345.68 \\
\hline PCM13 & Processing of Used Cars VAR 2 & $2,41,065$ INR per car & 369.54 \\
\hline PCM14 & Discarding Cost of VAR 1 & 13,500 INR per car & 15.29 \\
\hline PCM15 & Discarding Cost of VAR 2 & 15,700 INR per car & 22.98 \\
\hline PCM16 & Indirect cost of Ancillary Suppliers Utilisation & $3,06,275 \mathrm{INR}$ & 489.49 \\
\hline PCM17 & Indirect cost of Assembly Plants Utilisation & $1,83,765 \mathrm{INR}$ & 542.14 \\
\hline PCM18 & Indirect cost of Dealers Utilisation & $1,10,259 \mathrm{INR}$ & 404.85 \\
\hline PCM19 & Cars collected by collection centres & $\%$ & $39 \%(1465,1501,1478,1482)$ \\
\hline PCM20 & Parts re-sent to assembly plants & $\%$ & $67 \%(6443,6498,6478,6412)$ \\
\hline PCM21 & Cars re-sent to stores & $\%$ & $33 \%(490,481,493486)$ \\
\hline PCM22 & Materials disposed for land-filling & $\%$ & $40 \%(2918,2922,2896,2916)$ \\
\hline
\end{tabular}


Table 6: Effect of changing demands $\left(\Delta_{i}\right)$ in strategy 1D

\begin{tabular}{|c|c|c|c|c|c|c|c|c|c|c|c|c|c|c|c|c|c|c|}
\hline & PCM1 & PCM2 & PCM3 & PCM4 & PCM5 & PCM6 & PCM7 & PCM8 & PCM9 & PCM10 & PCM11 & PCM12 & PCM13 & PCM14 & PCM15 & PCM16 & PCM17 & PCM18 \\
\hline \multicolumn{19}{|l|}{ Strategy 1} \\
\hline $5 \%$ & 2,08,084.07 & 768.63 & $1,107.25$ & $1,252.26$ & 248.00 & 182.13 & 99.38 & 60.60 & 34.53 & $2,115.95$ & $2,381.14$ & 362.96 & 388.02 & 16.05 & 24.13 & 513.96 & 569.25 & 425.09 \\
\hline $10 \%$ & $2,28,892.47$ & 845.49 & $1,217.97$ & $1,377.49$ & 272.80 & 200.35 & 109.32 & 66.66 & 37.99 & $2,327.54$ & $2,619.25$ & 399.26 & 426.82 & 17.66 & 26.54 & 565.36 & 626.17 & 467.60 \\
\hline $15 \%$ & $2,63,226.34$ & 972.32 & $1,400.67$ & $1,584.11$ & 313.72 & 230.40 & 125.72 & 76.65 & 43.69 & $2,676.68$ & $3,012.14$ & 459.15 & 490.84 & 20.31 & 30.52 & 650.17 & 720.10 & $\mathbf{5 3 7 . 7 4}$ \\
\hline $20 \%$ & $3,15,871.61$ & $1,166.78$ & $1,680.80$ & $1,900.93$ & 376.46 & 276.48 & 150.86 & 91.98 & 52.42 & $3,212.01$ & $3,614.57$ & 550.98 & 589.01 & 24.37 & 36.63 & 780.20 & 864.12 & 645.29 \\
\hline $25 \%$ & $3,94,839.51$ & $1,458.48$ & 2,101.00 & $2,376.17$ & 470.58 & 345.60 & 188.58 & 114.98 & 65.53 & $4,015.01$ & $4,518.21$ & 688.72 & 736.26 & 30.46 & 45.78 & 975.25 & $1,080.15$ & 806.61 \\
\hline $30 \%$ & $5,13,291.37$ & $1,896.02$ & 2,731.30 & 3,089.02 & 611.75 & 449.28 & 245.15 & 149.47 & 85.19 & $5,219.52$ & $5,873.67$ & 895.34 & 957.14 & 39.60 & 59.52 & $1,267.82$ & $1,404.19$ & $1,048.60$ \\
\hline $35 \%$ & $6,92,943.35$ & $2,559.63$ & $3,687.25$ & $4,170.17$ & 825.87 & 606.52 & 330.95 & 201.79 & 115.00 & $7,046.35$ & 7,929.46 & $1,208.71$ & $1,292.14$ & 53.46 & 80.35 & $1,711.56$ & $1,895.66$ & $1,415.61$ \\
\hline $40 \%$ & $9,70,120.68$ & 3,583.48 & $5,162.16$ & $5,838.24$ & $1,156.21$ & 849.13 & 463.34 & 282.51 & 161.01 & $9,864.89$ & $11,101.24$ & $1,692.20$ & $1,809.00$ & 74.85 & 112.49 & $2,396.18$ & $2,653.92$ & $1,981.85$ \\
\hline
\end{tabular}

Table 7: Effect of changing collection rate $\left(v_{s} \%\right)$ in strategy 1D

\begin{tabular}{|c|c|c|c|c|c|c|c|c|c|c|c|c|c|c|c|c|c|c|}
\hline & PCM1 & PCM2 & PCM3 & PCM4 & PCM5 & PCM6 & PCM7 & PCM8 & PCM9 & PCM10 & PCM11 & PCM12 & PCM13 & PCM14 & PCM15 & PCM16 & PCM17 & PCM18 \\
\hline \multicolumn{19}{|l|}{ trategy 1} \\
\hline $5 \%$ & $2,04,120.56$ & 753.99 & $1,086.16$ & $1,228.41$ & 243.28 & 178.66 & 97.49 & 59.44 & 33.88 & $2,075.65$ & $2,335.78$ & 356.05 & 380.63 & 15.75 & 23.67 & 504.17 & 558.40 & 417.00 \\
\hline $10 \%$ & $2,24,532.61$ & 829.39 & $1,194.77$ & $1,351.25$ & 267.60 & 196.53 & 107.24 & 65.39 & 37.26 & $2,283.21$ & $2,569.36$ & 391.66 & 418.69 & 17.32 & 26.04 & 554.59 & 614.24 & 458.70 \\
\hline $15 \%$ & $2,58,212.51$ & 953.80 & $1,373.99$ & $1,553.94$ & 307.74 & 226.01 & 123.32 & 75.19 & 42.85 & $2,625.69$ & $2,954.76$ & 450.40 & 481.49 & 19.92 & 29.94 & 637.78 & 706.38 & $\mathbf{5 2 7 . 5 0}$ \\
\hline $20 \%$ & $3,09,855.01$ & $1,144.56$ & $1,648.78$ & $1,864.72$ & 369.29 & 271.21 & 147.99 & 90.23 & 51.42 & $3,150.83$ & $3,545.72$ & 540.48 & 577.79 & 23.91 & 35.93 & 765.34 & 847.66 & 633.00 \\
\hline $25 \%$ & $3,87,318.76$ & $1, \mathbf{4 3 0 . 7 0}$ & $2,060.98$ & $2,330.91$ & 461.62 & 339.01 & 184.99 & 112.79 & 64.28 & $3,938.54$ & $4,432.15$ & 675.61 & 722.24 & 29.88 & 44.91 & $\mathbf{9 5 6 . 6 7}$ & $1,059.57$ & 791.25 \\
\hline $30 \%$ & $5,03,514.39$ & $1,859.91$ & $2,679.27$ & $3,030.18$ & 600.10 & 440.72 & 240.48 & 146.63 & 83.57 & $5,120.10$ & $5,761.79$ & 878.29 & 938.91 & 38.85 & 58.39 & $1,243.67$ & $1,377.44$ & $1,028.62$ \\
\hline $35 \%$ & $6,79,744.43$ & $2,510.87$ & $3,617.02$ & $4,090.74$ & 810.14 & $\mathbf{5 9 4 . 9 7}$ & 324.65 & 197.95 & 112.81 & $6,912.13$ & 7,778.42 & $1,185.69$ & $1,267.53$ & 52.44 & 78.82 & $1,678.96$ & $1,859.55$ & $1,388.64$ \\
\hline $40 \%$ & $9,51,642.20$ & $3,515.22$ & $5,063.83$ & $5,727.04$ & $1,134.19$ & 832.96 & 454.51 & 277.12 & 157.94 & $\mathbf{9 , 6 7 6 . 9 9}$ & $10,889.79$ & $1,659.96$ & $1,774.54$ & 73.42 & 110.35 & $2,350.54$ & $2,603.37$ & $1,944.10$ \\
\hline
\end{tabular}


Table 8: Effect of changing capacities of ancillary suppliers, assembly plants and dealers in strategy 1D

\begin{tabular}{|c|c|c|c|c|c|c|c|c|c|c|c|c|c|c|c|c|c|c|}
\hline & PCM1 & PCM2 & PCM3 & PCM4 & PCM5 & PCM6 & PCM7 & PCM8 & PCM9 & PCM10 & PCM11 & PCM12 & PCM13 & PCM14 & PCM15 & PCM16 & PCM17 & PCM18 \\
\hline \multicolumn{19}{|l|}{ eg 1} \\
\hline $5 \%$ & $2,10,065.82$ & 775.95 & $1,117.79$ & $1,264.19$ & 250.36 & 183.87 & 100.33 & 61.17 & 34.86 & $2,136.10$ & 2,403.82 & 366.42 & 391.71 & 16.21 & 24.36 & 518.86 & 574.67 & 429.14 \\
\hline $10 \%$ & $2,31,072.40$ & 853.55 & $1,229.57$ & $1,390.61$ & 275.40 & 202.25 & 110.36 & 67.29 & 38.35 & $2,349.71$ & $2,644.20$ & 403.06 & 430.88 & 17.83 & 26.79 & 570.75 & 632.14 & 472.06 \\
\hline $15 \%$ & $2,65,733.26$ & 981.58 & $1,414.01$ & $1,599.20$ & 316.71 & 232.59 & 126.92 & 77.38 & 44.10 & $2,702.17$ & $3,040.83$ & 463.52 & 495.52 & 20.50 & 30.81 & 656.36 & 726.96 & 542.86 \\
\hline $20 \%$ & 3,18,879.91 & $1,177.89$ & $1,696.81$ & $1,919.04$ & 380.05 & 279.11 & 152.30 & 92.86 & 52.92 & $3,242.60$ & 3,648.99 & 556.23 & 594.62 & 24.60 & 36.98 & 787.63 & 872.35 & 651.44 \\
\hline $25 \%$ & 3,98,599.89 & $1,472.37$ & 2,121.01 & 2,398.80 & 475.06 & 348.89 & 190.37 & 116.08 & 66.15 & $4,053.25$ & $4,561.24$ & 695.28 & 743.27 & 30.75 & 46.22 & 984.54 & $1,090.43$ & 814.30 \\
\hline $30 \%$ & $5,18,179.86$ & $1,914.08$ & $2,757.31$ & $3,118.44$ & 617.58 & 453.56 & 247.49 & 150.90 & 86.00 & $5,269.23$ & $5,929.61$ & 903.87 & 966.26 & 39.98 & 60.09 & $1,279.90$ & $1,417.56$ & $1,058.58$ \\
\hline $35 \%$ & $6,99,542.81$ & $2,584.01$ & $3,722.37$ & $4,209.89$ & 833.73 & 612.30 & 334.11 & 203.71 & 116.10 & $7,113.46$ & $8,004.97$ & $1,220.22$ & $1,304.45$ & 53.97 & 81.12 & $1,727.86$ & $1,913.71$ & $1,429.09$ \\
\hline $40 \%$ & $9,79,359.93$ & $3,617.61$ & $5,211.32$ & $5,893.84$ & $1,167.22$ & 857.22 & 467.75 & 285.20 & 162.54 & $9,958.84$ & $11,206.96$ & $1,708.31$ & $1,826.22$ & 75.56 & 113.56 & $2,419.00$ & $2,679.19$ & $2,000.72$ \\
\hline
\end{tabular}

Combination of three effects is presented in Figure 7.

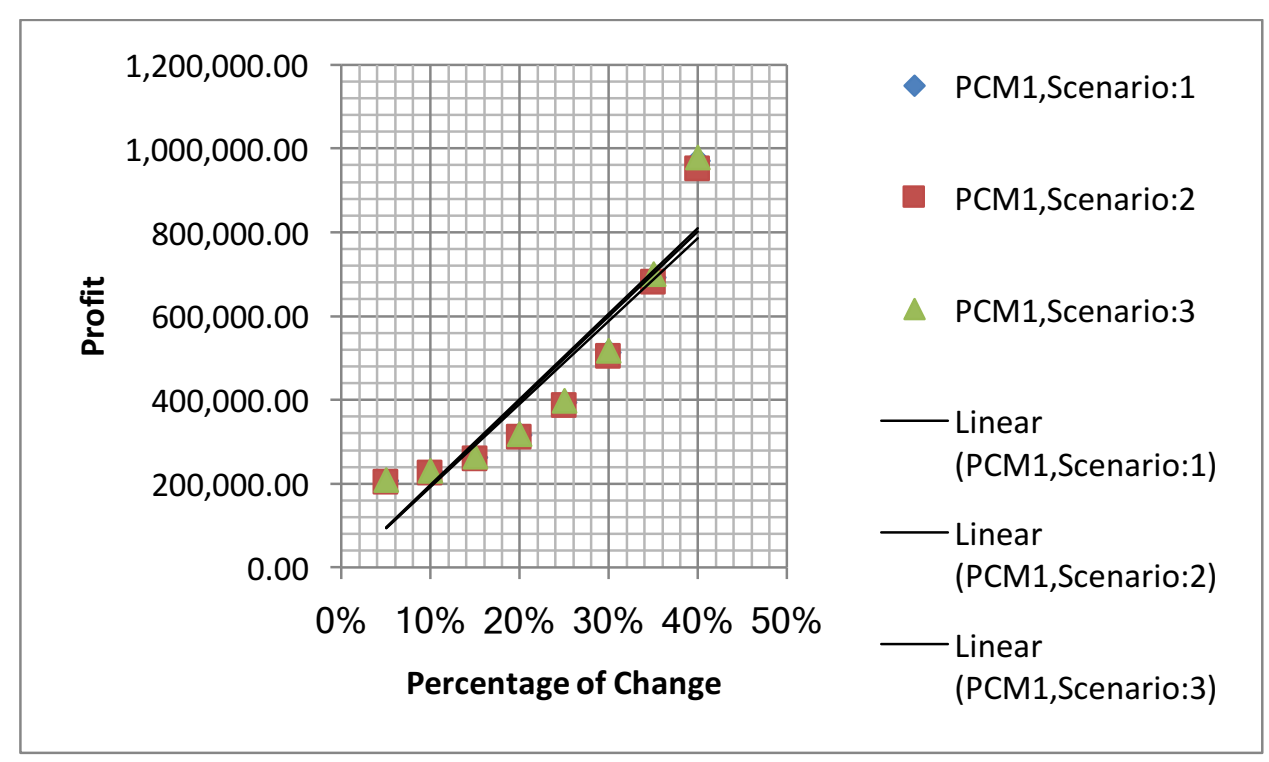

Fig 7: Sensitivity analysis plot for PCM1 (INR) in all three scenarios for strategy 1D. 
The results obtained for the computational experiments and sensitivity analysis on realistic instances had provided some of the following significant insights:

(1) Based on the current estimates, refurbishing and fixed costs do not seem to be as important as the cost of transportation and purchasing. Total transportation cost is the dominant factor in all operational costs.

(2) A $40 \%$ increment in demand of new car causes a $(100-79.57) \%=20.43 \%$ reduction in processing cost of used cars (PCM 12).

(3) If the decision-maker increases the collection rate from $5 \%$ to $40 \%$, the total cost could be decreased by $(100-80.63) \%=19.37 \%(\mathrm{PCM} 2)$.

(4) A $40 \%$ increase in capacities of ancillary suppliers, assembly plants and dealers leads to a reduction in total cost of only $(100-89.79) \%=10.21 \%(\mathrm{PCM} 16),(100-79.76) \%=20.24 \%(\mathrm{PCM} 17)$ and $(100-$ $80) \%=20 \%$ (PCM 18), respectively. Thus, OEM can prioritize facilities for capacity enhancement to decrease the total cost.

This analysis signifies that, $40 \%$ increment in demand, collection rate and capacity impacting minimum $10.21 \%$ to maximum $20.43 \%$ of reduction in certain costs imply profitability. So, viability of recovery program is significantly dependent on substantial growth of refurbished automobile market. Green image branding, take-back laws are most effective way of imposing recovery program in the market.

Finally, if decision makers of OEM want to change or increase the number of strategies for this network, they would do the sensitivity analysis for all the eight strategies and compute RLTs and/or delivery limits accordingly. Now, if the decision makers do an empirical study on the basis of historical data, they may find out a pattern of the input parameters of this model. So, the decision makers could plan for the entire manufacturing cycle and remanufacturing cycle by simulating this model again and again with different patterns of input. This model will help the decision makers of automotive industries to achieve a sustainable and green production system with longterm benefits. Decision makers of OEM may also compare the strategies with the effect taking place at the aforesaid performance criterion measurement (PCM) for changing a percentage of key input parameters. Sensitivity analysis helps the automotive manufacturers in decision making related to start of any such recovery program. 


\section{Conclusion}

In this research, a strategic CLSC network is considered to meet the requirements of the auto industry. It may also be used for different industries' requirements in green image branding. A mixed integer programming model has been developed that embraces a multi-parts, multi-period, multi-product and multi-strategy forward and reverse chain. Using a realistic forward distribution network as a base case, we have explored a number of strategies for closed-loop network, where the effects on the various performance indicators are considered for the problem. Issues such as demand, capacity and collection rates were investigated. Moreover, the sequential equations are formulated to compute the realization time or delivery limits for swapping each strategy. This paper contributes to the literature by: (1) developing a strategic, integrated, multi-echelon, multi-period, multi-product, multi-parts and multi-product mixed integer linear programming model to optimize the production and distribution planning for a CLSC network; (2) understanding realization time and delivery limits are considered for each combination of strategies and / or delivery limits, which decision makers could change; (3) considered procurement (raw material and ELV) and reintegration (used-parts/products) costs to manage the realistic trade-off problem; (4) developing an experimental set up for sensitivity analysis that sheds light on the interactions of various performance indicators using the proposed model through a sample problem. For future research, a Bayesian belief network model can help in analysing different modes of risks involved to make the auto recovery program profitable and viable with mitigation strategies. In addition, a Markovian model could be developed in place of sequential equations to find out the distinct moments in the planning horizon for swapping strategies. The pricing strategy for ELVs is also a significant challenge, which may be another potential area for further research and investigation. :

\section{Acknowledgement}

The authors acknowledge the support provided by European Union EuropeAid-funded Project "EUIndia Research \& Innovation Partnership for Efficient and Sustainable Freight Transportation (REINVEST)," Contract Number: R/141842. The contents of this publication are the sole responsibility of the authors of this paper and can in no way be taken to reflect the views of the European Union.

\section{References}

Akcal, E., Cetinkaya, S., and Uster, H., 2009. Network design for reverse and closed-loop supply chains: an annotated bibliography of models and solution approaches. Networks, 53 (3), 231-248. 
Bhattacharyya, S., \& Dan, P. K. (2014). Trends in ERP Software and Justification for Development of Open Source Systems for Small-scale Businesses. Asia-Pacific Journal of Management Research and Innovation, 10 (4), $423-433$.

Clell, G. Harrell. (1991). Meeting the Transportation Aspirations of Developing Countries: Energy and Environmental Impacts. Energy and Environment in the 21st Century, (Cambridge, MA: The MIT Press), $247-249$.

Chen, J. M., \& Chang, C. I. (2012). The co-optative strategy of a closed-loop supply chain with remanufacturing. Transportation Research Part E: Logistics and Transportation Review, 48(2), 387-400.

Demirel, N.O” .and Go“ kcen, H., 2008. A mixed integer programming model for remanufacturing in reverse logistics environment.International Journal of Advanced Manufacturing Technology, 39 (11-12), 1197-1206.

Ferguson, M.E. and Souza, G.C., 2010. Closed-loop supply chains: new developments to improve the sustainability of business practice. New York: Springer.

Flapper, S.D.P., Nunen, J.A.E.E., and Wassenhove, L.N., 2005.Managing closed-loop supply chains. Boca Raton, FL:CRC Press.

Fleischmann, M., et al., 2001.The impact of product recovery on logistics network design. Production \& Operations Management, 10 (3), 156-173.

Forkenbrock, D.J., 2001. Comparison of external costs of rail and truck freight transportation. Transportation Research Part A, 35 (4), 321-337.

Guide, V.D.R., Jayaraman, V., and Jonathan, D.L., 2003.Building contingency planning for closed-loop supply chains with product recovery. Journal of Operations Management, 21 (3), 259-279.

Jayaraman, V., Guide Jr, V.D.R., and Srivastava, R., 1999. A closed-loop logistics model for remanufacturing. Journal of the Operational Research Society, 50 (5), 497-508. 
Jayaraman, V., 2006. Production planning for closed-loop supply chains with product recovery and reuse: an analytical approach. International Journal of Production Research, 44 (5), 981-998.

Manhendra Mohan, B. (2014). Production \& Operations End of Life Vehicle Recycling in India, International Journal of Scientific Research, 3(4), $1-2$.

Kannan, G., Haq, A.N., and Devika, M., 2009. Analysis of closed-loop supply chain using genetic algorithm and particle swarm optimization. International Journal of Production Research, 47 (5), 1175-1200.

Kannan, G., Sasikumar, P., and Devika, K., 2010. A genetic algorithm approach for solving a closed loop supply chain model: a case of battery recycling. Applied Mathematical Modeling, 34 (3), 655-670.

Krikke, H., Bloemhof-Ruwaard, J., and Van Wassenhove, L.N., 2003. Concurrent product and closed-loop supply chain design with an application to refrigerators. International Journal of Production Research, 41 (16), 3689-3719.

Lebreton, B., 2007. Strategic closed-loop supply chain management. New York: Springer.

Lee, J.-E., Gen, M., and Rhee, K.-G., 2009. Network model and optimization of reverse logistics by hybrid genetic algorithm.Computers \& Industrial Engineering, 56 (3), 951-964.

McGovern, S.M., 2009. Strategic planning models for reverse and closed-loop supply chains, by K.K. Pochampally, S. Nukala,and S.M. Gupta. International Journal of Production Research, 47 (23), 6777-6779.

Min, H., Ko, C.S., and Ko, H.J., 2006. The spatial and temporal consolidation of returned products in a closed-loop supplychain network. Computers \& Industrial Engineering, 51 (2), 309-320.

Ministry of Heavy Industries \& Public Enterprises, G. of I. (2006). Automotive Mission Plan 2006-2016. http://onlinelibrary.wiley.com/doi/10.1002/cbdv.200490137/abstract 
Neto, J.Q.F., et al., 2008. Designing and evaluating sustainable logistics networks. International Journal of Production Economics, 111 (2), 195-208.

E, Paksoy.T, Ö. 2013. A Mixed Integer Programming Model for a Closed-loop Supply-chain Network. International Journal of Production Research, 51(3), 718-734. doi:10.1017/CBO9781107415324.004

Paksoy, T., Bektas, T., and O“ zceylan, E., 2011. Operational and environmental performance measures in a multiproduct closed-loop supply chain. Transportation Research Part E, 47 (4), 532-546.

Pishvaee, M.R., Rabbani, M., and Torabi, S.A., 2011. A robust optimization approach to closed-loop supply chain network design under uncertainty. Applied Mathematical Modelling, 35 (2), 637-649.

Rogers, D.S. and Tibben-Lembke, R.S. 1998.Going backwards: reverse logistics trends and practices. Reverse Logistics Executive Council. Available from: http://www.rlec.org/reverse.pdf [Accessed 23 September 2011]. Schultmann, F., Zumkeller, M., \& Rentz, O. (2006). Modelling reverse logistic tasks within closed-loop supply chains: An example from the automotive industry. European Journal of Operational Research, 171, 1033-1050.

Shende, V. (2014). Analysis of Research in Consumer Behaviour of Automobile Passenger Car Customer. International Journal of Scientific and Research Publications, 4(2), 1-8.

Sheu, J.B., Chou, Y.H., and Hu, C., 2005. An integrated logistic operational model for green supply chain management. Transportation Research Part E, 41 (4), 287-313.

Shi, J., Zhang, G., and Sha, J., 2011. Optimal production planning for a multi-product closed loop system with uncertain demand and return. Computers \& Operations Research, 38 (3), 641-658.

Srivastava, S.K., 2007. Green supply chain management: a state of the art literature review. International Journal of Management Reviews, 9 (1), 53-80.

Ravi, V., Shankar R., 2013. Survey of reverse logistics practices in manufacturing industries: an Indian context. Benchmarking: An International Journal, 22 (5), 874 - 899.

Wang, H.-F.and Hsu, H.-W., 2010. A closed-loop logistic model with a spanning-tree based genetic algorithm. Computers \&Operations Research, 37 (2), 376-389.

Yang, G.-F., Wang, Z.-P., and Li, X.-Q., 2009.The optimization of the closed-loop supply chain network. Transportation Research Part E, 45 (1), 16-28. 